\title{
Looking Below the Surface: An Analysis of an Elementary Teacher Education Program Diversity Transformation
}

\author{
Patricia L. Bullock ${ }^{1}$, Karthigeyan Subramaniam² ${ }^{2}$ Lisa Buenaventura ${ }^{3}$, Incho Lee ${ }^{4}$ \\ Kennesaw State University ${ }^{1}$ \\ University of North Texas, Denton ${ }^{2}$ \\ University of Massachusetts, Boston ${ }^{3}$ \\ University of Wisconsin ${ }^{4}$
}

\begin{abstract}
The purpose of this article is to explore the "transformation" of one elementary teacher education program from traditional/hegemonic underpinnings to one that infused diversity throughout the program. The catalyst for transforming program curricula was the preparation process for initial professional accreditation through the National Council for the Accreditation of Teacher Education (NCATE). This inquiry was initiated as a result of a non-related research project in which we exploring perspectives of preservice teachers, who are members of underrepresented identity groups. It was through initial data gathering that we began to question the authenticity of the aforementioned transformation. For the purposes of this paper, we focus on the elementary teacher education program in which we all were faculty. Data collected and examined were from the research project initial interviews, course curricula (NCATE evidence), and our reflections on our other faculty experiences. Three key themes emerged from the analysis of datapropagating deficits through curricula and pedagogy, hegemonic understandings, and faculty discomfort. That is, data reveal that propagation of deficits and hegemonic practices may emanate from teacher educators who reflected potential (probable) discomfort with issues of diversity and social justice. We conclude with other questions, particularly reflected on the role of accreditation institutions.
\end{abstract}

Key Words: Diversity, Teacher Education, Elementary Education, Accreditation

\section{Introduction}

Schools of education have the potential to become major forces for social justice and change: places conducive to "critical inquiry and meaningful dialogue” [1]; places where democracy and social empowerment are emphasized. Such transformation involves processes that challenge and open up spaces for preservice teachers to question oppression, power, and privilege within global, societal, institutional, and individual contexts [2], [3], [4], [5], [6]. These processes also require that preservice teachers recognize dominant culture practices and norms and the multiplicity of identities and experiences that enter into their future classroom environments [7].

This process is not simple as research suggests preservice teachers often resist new knowledge that challenges their experiences with regard to the realities of oppression, power, and privilege [8], [9]. This resistance to learning is compounded by the growing disparities between teachers, who are predominantly white, female, middle-class, heterosexual, and abled, and the culturally and linguistically diverse student populations [10], [11], [12]). Moreover, many preservice teachers tend to cling to and defend discourses that privilege those of the dominant culture [13], [14]—discourses that deny opportunities for people who are seen as "Others," people who are underrepresented, and/or who are marginalized in society [15]. As such, preservice teachers often have difficulty considering their responsibility as educators to employ social justice curricula [16], [17]. Furthermore, once they have entered the field as "certified teachers," some have acknowledged their lack of effective preparation in working for social justice and change with diverse populations, despite the fact that their teacher 
education programs included a diversity component [18].

We acknowledge preservice teachers' resistances to diversity and social justice, and research indicates that stand-alone diversity/multicultural courses are insufficient to challenge these resistances [19], [20]. Therefore, we must go beyond the one-coursewonder and permeate issues of diversity and social justice. That is, we recognize that teacher educators and teacher education programs are responsible for providing experiences through/in which preservice teachers might overcome or begin to dismantle resistances [7], [20]. We also recognize that institutions at local, state, and national levels are cognizant of the need to focus on issues of diversity in schooling, and are compelling teacher education programs to attend to these issues through accreditation processes. With this in mind, the preparation process for initial professional accreditation through the National Council for the Accreditation of Teacher Education (NCATE) was used as a catalyst for transforming program curricula and permeating diversity throughout our teacher education program.

NCATE defines diversity as "Differences among groups of people and individuals based on ethnicity, race, socioeconomic status, gender, exceptionalities, language, religion, sexual orientation, and geographical area. The types of diversity necessary for addressing the elements on candidate interactions with diverse faculty, candidates, and $\mathrm{P}-12$ students are stated in the rubrics for those elements." Furthermore, NCATE accreditation requires evidence within teacher education program conceptual framework, curricula, field experiences, faculty, and candidate information that reflect an "acceptable" degree of attention to diversity issues. At the time of the program's review, all required course curricula indicated an incorporation of diversity issues.

At the start of the academic year that followed the program's national accreditation, we initiated a research project exploring the perspectives of preservice teachers, who are members of underrepresented identity groups, within our elementary teacher education program. It was through our initial interviews with the participants that we began to question the authenticity of the aforementioned curricula diversity transformation. This questioning led us to the purpose of this article, which is to explore the "transformation" of our elementary teacher education program from traditional/hegemonic underpinnings to one that infused diversity throughout the program.

In this article, we begin with our methodology, beginning with brief descriptions of the catalyst research project then moving to the curricular analysis methodology. Next, we explore and discuss our findings that suggest programmatic diversity incorporation as "skin deep." Finally, we conclude with questions that need to be considered and addressed, particularly as related to national - or other level - accreditation.

\section{Methodology}

\subsection{Context}

The site for this inquiry is in a teacher education department at a small university, which is also one campus of a multi-campus public land-grant university in the Mid-Atlantic region of the United States. The university is located within an urban area, but also enjoys suburban and rural geographic proximity. Undergraduate and graduate programs offered within the teacher education department include initial certification for elementary education and for secondary mathematics, English, and social studies, and advance certification in teaching and curriculum.

For the purposes of this paper, we focus on the elementary teacher education program in which we all were faculty, and we limit the reflections to the three years of self-study, 2004-05 through 2006-07, the period during which faculty prepared for NCATE review. Preservice teachers enrolled in the university's elementary teacher education programs were predominantly white, female, and middle class. In addition, during the three years of self-study accreditation preparation, the number of elementary education faculty from underrepresented groups increased from $16 \%$ to just over $26 \%$.

\subsection{Authors' Identities and Roles}

Identities. While we are similar in our worldviews and in our social justice perspectives and frameworks, we also differ in ways that have influenced each of our paths, our journeys to such perspectives. Patricia Bullock self-identifies as white, female, native English speaker, U.S.-born, and lesbian, who has a mathematics educator background. Karthigeyan Subramaniam self-identifies as Asian, male, and multi-lingual, who has a science educator 
background. Lisa Buenaventura self-identifies as multiracial, multiethnic, U.S.-born, female, heterosexual and married, who has an educational leadership and a TESOL educator background. Incho Lee identifies as Asian, female, and non-native English speaker, who has a TESOL educator background.

Roles. In July 2004, with the university administration's and the teacher education faculty's desires for program national accreditation, Lisa was hired as the teacher education's unit coordinator for the pursuit of national accreditation through the National Council for the Accreditation of Teacher Education (NCATE). Charged with leading the alignment of the teacher education programs with core national standards (such as the National Council of Teachers of Mathematics standards), Commonwealth standards, as well as NCATE standards, sub-committees were assembled around each of the NCATE six standards. For the Standard IV (Diversity) committee, Patti served as a co-chair, Lisa and Incho served as members, and Karthi periodically served as a reviewer of the diversity data as well as the diversity portion of the Institutional Report.

\subsection{Underrepresented Identity Preservice Teacher Research Methodology}

Briefly, there were four of the over 40 preservice teachers within the two elementary education cohorts who identified as a member of an underrepresented group. All four agreed to participate in the research project. Three identified as African American females, one identified as an Asian American male. Semi-structured individual interviews were created and implemented to gauge the participants' perspectives of their experiences within a teacher education program that has few underrepresented candidates enrolled. Interviews were conducted during their final year of the program-at the beginning of their discipline methods courses, within their field experiences connected to the methods courses, and during their student teaching practica.

\subsection{Curricula Analysis Reflections}

Reflections and subsequent questions offered for this paper presentation are based on our experiences within the Standard IV Committee within/from the data sources below.
Curricula Analysis. We first examine our curricula analysis as related to NCATE Standard 4a, Design, Implementation and Evaluation of Curriculum and Experiences. The process of curricular analysis began with identifying a collective operational definition of "diversity" by the teacher education faculty. The Standard IV Committee emailed the NCATE definition of diversity to all teacher education faculty members, who were asked to submit any additional considerations. All feedback were compiled and presented at a teacher education faculty meeting for consensus during which the following was constructed:

To align with the strategic direction of the University [system] and [this university within the University system], the Teacher Education Unit within the School of Behavioral Sciences and Education at [this university] developed a very specific definition of diversity that we believe reflects the knowledge, skills, and dispositions that should be evident in both our candidates and our faculty. Diversity means differences related to identities, subjectivities, experiences, and cultures. It may incorporate attributes such as race, gender identity, ethnicity, sexual identity, religious beliefs, geographical location, age, socioeconomic status, local/state/regional/global/country of origin, culture, language, physical size, ability, learning style, educational background, social status, employment, professional status, marital status, historical experiences, traditions, customs and rituals, values and lifestyles. Acceptance of diversity acknowledges and respects people's total identity and social existence based on their individual social values and beliefs to ensure social justice for everyone. Our definition of diversity guides and influences the recruitment and retention of candidates and faculty, our research and pedagogy, our programming, and our outreach and service to both internal and external communities.

We then asked faculty to identify goals, objectives, and assessments from their syllabi which reflected the faculty's diversity definition. Finally, we used the faculty's diversity definition and the NCATE rating system to analyze syllabi collected from the teacher 
education faculty. Feedback and suggestions were provided by the Standard IV (Diversity) committee in an effort to demonstrate explicit course alignment with NCATE standards and the teacher education faculty's definition. The resulting feedback and suggestions were presented and discussed for further input and insights during the multiple NCATE meetings chaired by the NCATE steering committee and by the Standard IV committee. Teacher education faculty were given multiple opportunities to discuss Standard IV committee's analysis of syllabi with Standard IV committee members and other teacher education faculty. At the time of accreditation review, all elementary education courses incorporated issues of diversity. Furthermore, NCATE Standard 4a was deemed acceptable and without any restrictions or any indicated "Areas For Improvement" (AFI). The "revised" syllabi were examined for the purposes of this study. Particular attention was paid to assessments.

Professional Development. The university offered multiple professional development opportunities for faculty that addressed issues of diversity in myriad ways. However, we focus on one professional development that was created and implemented by members of the Standard IV committee, and that coincided with a (required) faculty meeting. The professional development workshop was based on the Cultural Learning Process [20]. Faculty were asked to fill out a questionnaire based on 12 identities and bring their responses to the workshop. To begin the workshop, Standard IV members presented a framework for the workshop-one that explored the intersections of power, privilege, and oppression. Next, four members of the committee shared narratives related to one (self) identity that were particularly significant to their experiences and worldviews. Finally, small group discussions about faculty members' identities and cultural lenses were facilitated by committee members.

Other Experiences. We include other experiences such as faculty meetings - in which we perceived a non-inclusive environment or attitude regarding Others.

\section{Findings and Discussion}

Three key findings emerged from the analysis of the teacher education unit's definition of diversity and the operational definition of diversity in syllabi. First, curricula within syllabi continued to present content and information about underrepresented students as problems or as issues of diversity as relevant to classroom management or "at-risk" children. This perspective on curricula suggested the continued superficial understanding of diversity and as a means to propagate deficits. Second, analysis revealed hegemonic pedagogies and/or understandings that promoted and reinforced dominant cultural practices of schooling underscoring the teacher education unit's curricula for teacher education. Finally, the analysis revealed that the propagation of deficits and hegemonic practices seemed to emanate from teacher educators who reflected potential (probable) discomfort with issues of diversity and social justice, particularly those who had dominant culture identities and who have rarely been asked to think about their (subjectivity and/or identity) privileges and power.

\subsection{Propagating Deficits}

The first revelation illuminated a few curricula in which concepts and strategies to address diverse ability levels and behavioral issues were introduced, yet presented information about learners in urban environments with an emphasis on racial and ethnic differences and stereotypes rather than address the range of socio-cultural factors impacting these learners. An example of such stereotyping was a handout given to candidates in one course that summarily categorized racial groups (African American, Asian American, Caucasian, Hispanic/Latino, Native American) according to "expected" attitudes and behaviors. Rather than inform candidates in order to build cultural competence, it reinforced existing belief systems about groups rather than approaching individuals with unique characteristics, histories, and talents. The most unfortunate result was that candidates were sharing this information across courses and cohorts, thus regenerating a specific worldview about difference.

Other curricula highlighted deficit understandings within course goals and course assessments. For example, within the course exploring "special learners," a course designed to address issues of inclusive education and English language learners, issues of "urban schooling" problematics were identified as one of the primary course goals. One research participant stated that she felt this course goal defined diversity as a "faulty thing" to be repaired or as a "problem" to be resolved. In addition, 
in the standard lesson plan, which was also the only "diversity" evidence for several core courses, "diversity" was assessed in two criteria listed toward the end of the assignment description. One criterion was "accommodations/adaptations," which evaluated how effectively "Modifications address all students" individual needs." The other criterion that may have been remotely connected with diversity was "Connections to home-community," for which an exemplary rating was described as "Activity reflects strong link to home \& community." This criterion would have been diversity-focused only in the case of identified "diverse" students.

Further evidence came from analysis of teacher candidates' perceptions of the syllabi and the focus of diversity within their methods courses. For example, candidates assumed that the presence of non-White students, particularly African-American students in the classroom mooted the need to integrate diversity. This inclination towards integrating diversity in response to the presence of the "other" in most cases was due to the "other" being conceptualized as a problem that needed to be resolved. Clearly, candidates were being mis-educated, that is, they were being mis-informed that diversity was a problem to be tackled with and resolved rather than an already integral and inherent part of educative experiences.

\subsection{Hegemonic Understandings}

The second theme revealed the hegemonic understandings and practices of teacher education faculty. Much like preservice and inservice teachers who identify as white, male, middle class, abled, heterosexual, and so forth, teacher educators may also adhere to discourses of deficit, discourses of privilege, and dominant culture (and unquestioned) understandings of schooling. These teacher educators may not have been called to examine how they are complicit with or advocates of hegemonic practices. Teacher educators' hegemonic understandings of diversity were evident in one professional development session, which was aimed at understanding one's Self and one's identities. Reflecting on our experiences, we noted that several white, middle class, heterosexual faculty resisted considering more challenging identity issues. For example, one male faculty member presented a case of "reverse discrimination," as he felt that he was a "minority" (i.e. lacks power or privilege) within education because he was white and male even though he was a full professor.

Other examples of hegemonic understandings were revealed in our reflections on department meetings. During one the meeting, a tenured faculty member suggested that the "accommodations/adaptation" of the lesson plan was sufficient to "cover" diversity. In another meeting, an African American female preservice teacher's academic abilities were questioned. During this meeting, one faculty member commented that this preservice teacher was extremely quiet during class and rarely provided her opinion or experiences, thus exhibits a "lack of cognitive process." The abilities of a white female preservice teacher demonstrating a similar quiet demeanor were never questioned.

\subsection{Discomfort}

Regardless of the commitment to diversity some faculty members had articulated at the start of the accreditation endeavor, the realities of classroom discourses seemed to undermine that commitment. Whether consciously or unconsciously, some faculty members seemed unable or unwilling to address issues of diversity directly, and/or seemed to cause discomfort or discordance in the classroom. This avoidance or discomfort also suggested that faculty members themselves may have had limited knowledge and exposure to the range of potential diversity within the classroom and the larger community and, therefore, limited development of their cultural competence. Their intentions may have been sincere, but they may have lacked the depth of knowledge and experience to understand what it was/is like to be Other.

\section{Conclusion}

Through this inquiry, we discovered that teacher educators were willing to incorporate syllabi revision suggestions made by the Standard IV committee in ways that articulated elements of diversity. However, as evidenced by preservice teacher perspectives, the pedagogical practices employed by teacher educators reflected the course as status quo. Furthermore, several teacher educators' language and behaviors within program professional spaces (professional development and meetings) reflected hegemonic understandings of teacher education. That is, some of the course curricula transformations appeared only on paper - they were skin deep. 
It is also clear that the preparation process for professional accreditation through the National Council for the Accreditation of Teacher Education (NCATE) used as a catalyst for transforming program curricula and permeating diversity throughout our teacher education program was, at best, superficial. Diversity was often not addressed in critical ways, if at all, and at times addressed in ways that maintain the hegemonic status quo. Problematic, too, is that the diversity evidenced by the program were deemed as "acceptable" by NCATE Board of Examiners, and thus contributing to the program's national accreditation. That is, through accreditation, a stamp-of-approval was given that most likely encouraged the program's continuance of such practices.

This reflective exploration has raised some questions and issues for future inquiry. One issue is teacher educator dispositions. As Merryfield (2000) suggests, teacher educators teach what they know, and rate student dispositions according to their lenses. How might we provide teacher educators spaces in which they can come to understand critical diversity in order to incorporate such lenses in the courses they teach? Might it be worthwhile to investigate teacher educators' dispositions and understandings of diversity as a standard within accreditation processes? If what is assessed is valued, then how might Promotion and Tenure criteria incorporate teacher educators' practices and understandings of diversity within service, teaching, and/or scholarship? Perhaps most importantly, how might teacher education programs approach diversity as a community endeavor that leads to programmatic underpinnings and curricular, pedagogical, and field experiences practices?

\section{References}

[1] Giroux, H., and McLaren, P., (1996). Teacher education and the politics of engagement: The case for democratic schooling. In P. Leistyna, A. Woodrum, \& S. Sherblom (Eds.), Breaking free: The transformative power of critical pedagogy (301-332). Cambridge, MA: Harvard Educational Review.

[2] Gollnick, Donna M., and Chinn, Philip C. (2002). Multicultural education in a pluralistic society ( $6^{\text {th }}$ Ed.). Upper Saddle River, NJ: Merrill Prentice Hall.

[3] Howard, G. R., (2006). We can't teach what we don't know: White teachers, multiracial schools ( $\left.2^{\text {nd }} E d\right)$. New York: Teachers College Press.
[4] McIntyre, A., (1997). Making meaning of whiteness: Exploring racial identity with white teachers. New York: SUNY.

[5] Sleeter, C. E., (2001). Preparing teachers for culturally diverse schools: Research and the overwhelming presence of whiteness. Journal of Teacher Education, 52 (2). 94106.

[6] Bullock, P. L., and Freedman, D. M. (2006). (Re)visions to a secondary teacher education course: Trials and triumphs in attempting to disrupt hegemonic understandings and performances of education. Teaching and Teacher Education, 22, 135-262.

[7] Pattnaik, J., and Vold, E. B. (1998). Preservice teachers' multicultural literacy: Are we missing the forest for the trees? Equity \& Excellence in Education, 31 (3), 73-84.

[8] Ukpokodu, N., (2002). Breaking through preservice teachers' defensive dispositions in a multicultural education course: A reflective practice. Multicultural Education, 2533.

[9] Gay, G., (2005). Politics of multicultural teacher education. Journal of Teacher Education, 56 (3), 221-228.

[10] Tatum, B. D., (2003). "Why are all the black kids sitting together in the cafeteria?" and other conversations about race (Revised ed). New York: Basic Books.

[11] Zeichner, K. M., (2003). The adequacies and inadequacies of three current strategies to recruit, prepare, and retain the best teachers for all students. Teachers College Record, 105(3), 490-519.

[12] Powell, L. C., (1997). The achievement (k)not: Whiteness and "black underachievement." In Michelle Fine, Lois Weis, Linda C. Powell, \& L. Mun Wong (Eds.), Off white: Readings on race, power, and society, (3-12). New York: Routledge.

[13] Wade, R. C., (1998). Brick walls and breakthroughs: Talking about diversity with white teacher education students. Social Education, 62, 84-87.

[14] Kumashiro, Kevin K., (2002). Troubling education: Queer activism and antioppressive pedagogy. New York: RoutledgeFalmer.

[15] Bell, L. A., and Griffin, P., (2007). Designing social justice education courses. In M. Adams, L. A. Bell, \& P. Griffin (Eds) Teaching for diversity and social justice $\left(2^{\text {nd }}\right.$ ed), 67-87. New York: Routledge.

[16] Gallavan, N. P. (2000). Multicultural education at the academy: Teacher educators' challenges, conflicts, and 
coping skills. Equity \& Excellence in Education, 33 (3), 511.

[17] Thompson, P. B., and Biffle, R. L. (2008). Connections, constructions and collages: Initiating dialogues on diversity in teacher education courses. Curriculum and Teaching Dialogue, 10 (1 \& 2), 165-175.

[18] Garmon, M. A., (2004). Changing preservice teahers’ attitudes/beliefs about diversity: What are the critical factors? Journal of Teacher Education, 55 (3), 201-213.

[19] Valentín, S., (2006). Addressing diversity in teacher education programs. Education, 127 (2), 196-202.

[20] Cushner, K. McClelland, A., and Safford, P. (2006). Human diversity in education: An integrative approach $\left(5^{\text {th }}\right.$ ed). New York: McGraw-Hill. 